\title{
On the Influence of Segment Length in Pw-Tsm Doppler Systems
}

\author{
Wilhjelm, Jens E.
}

Published in:

Proceedings of the Annual International Conference of the IEEE Engineering in Medicine and Biology Society

Publication date:

1992

Document Version

Publisher's PDF, also known as Version of record

Link back to DTU Orbit

Citation (APA):

Wilhjelm, J. E. (1992). On the Influence of Segment Length in Pw-Tsm Doppler Systems. In Proceedings of the Annual International Conference of the IEEE Engineering in Medicine and Biology Society (Vol. Volume 5, pp. 2144-2145). IEEE.

\section{General rights}

Copyright and moral rights for the publications made accessible in the public portal are retained by the authors and/or other copyright owners and it is a condition of accessing publications that users recognise and abide by the legal requirements associated with these rights.

- Users may download and print one copy of any publication from the public portal for the purpose of private study or research.

- You may not further distribute the material or use it for any profit-making activity or commercial gain

- You may freely distribute the URL identifying the publication in the public portal

If you believe that this document breaches copyright please contact us providing details, and we will remove access to the work immediately and investigate your claim. 


\title{
On the Influence of Segment Length in PW-tsm Doppler Systems
}

\author{
Jens E. Wilhjelm, Member, IEEE \\ Electronics Institute, Technical University of Denmark, Building 349 \\ DK-2800 Lyngby, Denmark
}

\begin{abstract}
Two different signal processing techniques can be used for blood velocity measurements with Pulsed Wave (PW) Doppler. These are based on measurement of phase shift and time shift, respectively. The first technique is based on a correlation measurement scheme, which features inherent velocity aliasing. The second technique, which is based on the location of the peak in the crosscorrelation function of consecutive received signal segments, is in principle free of this problem. However, as noise are present and finite signal segments are used, only an estimate of the cross-correlation function is available. Thus, as detection of velocities greater than the aliasing velocity will require searching for a peak in a function with several peaks, the method is prone to detection of incorrect peaks. This paper investigates the effect of the length of the signal segments to be cross-correlated on the probability of incorrect detection.
\end{abstract}

\section{INTRODUCTION}

Recent advances in blood velocity measurements with pulsed (Doppler) ultrasound have made possible twodimensional mapping of the velocity of moving blood. In this technique, short tone burst of ultrasound in the $1-15 \mathrm{MHz}$ range is transmitted, and using the fact that the received signal is compressed/expanded due to the Doppler effect, the variation in time shift between transmitted and received signals can be measured. This can either be done by interpreting this time variation as a phase shift, or measuring it directly by cross-correlation. These two technique are called PW-psm (phase shift measurement) and PW-tsm (time shift measurement), respectively. ${ }^{[3]}$ In the latter technique, for each range cell, a segment (of length $T_{w}$ ) of one received signal is windowed out, delayed a time equal to the pulse repetition period, $T_{r}$, and cross-correlated with the next received signal. This will produce a cross-correlation function which oscillates with the transducer frequency. Assuming that the received signals have identical shape, the cross-correlation function will have a true peak at a time lag, $t_{0}$, which equals the relative time delay between two received signals. From this the velocity in direction of the transducer can be calculated as follows: $v=c t_{0} /\left(2 T_{r}\right)$, where $c$ is the propagation velocity of sound in the medium. An example of the cross-correlation

This work was supported by Brüel \& Kjar Medico Inc., T. B. Thrige, H\&M Skov, O. Bruun and Fisker \& Nielsen Foundations.

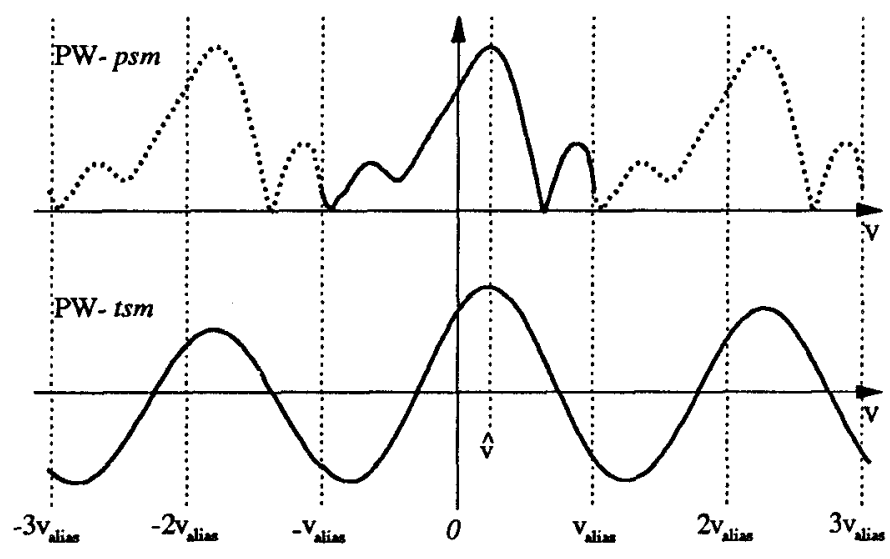

Fig. 1. Example of Doppler spectrum (top) for PW-psm and cross-correlation function (bottom) for PW-tsm.

function is indicated in Fig. 1, which also shows an example of a Doppler spectrum obtained with a PW-psm system. While only velocities within the aliasing velocity range $\left[-v_{\text {alias }} ; v_{\text {alias }}\right]$ can be detected with the PW-psm system, any velocity can in principle be detected with the PW-tsm system. However, as seen from Fig. 1, there is a risk of detecting a sidelobe. The probability of detecting a sidelobe (i.e. incorrect detection) decreases with increasing signal to noise ratio and increasing bandwidth of the transmitted pulse. ${ }^{[1,2]}$ In contrast, the probability is increasing with increasing loss of coherence between consecutive received signals (which is due to beam intensity modulation and velocity variation within the range cell) $^{[1,3]}$. Finally, as short signal segments (of length $T_{w}$ ) are used to calculated the cross-correlation function, only an estimate of this function is obtained. However, the longer the signal segments the better the estimate. This is of course consistent with the generalized Heisenberg uncertainty principle, in the sense that a particle's position and velocity can not be found simultaneously with arbitrarily high precision. In essence, a large segment length will yield a large range cell but at better velocity estimate (ignoring the velocity variation inside the range cell).

\section{SIMULATION STUDIES}

Simulations showing the effect of varying the integration time, $T_{w}$, in the cross-correlation function (i.e. the size of the range cell) have been performed. These simulations are carried out with the following parameters: $r m s$ Bandwidths of transmitted, received and noise signals: $1.2 \mathrm{MHz}$; Transducer 
frequency: $f_{0}=7 \mathrm{MHz} ; \mathrm{S} / \mathrm{N}: 15 \mathrm{~dB} ; T_{r}=66.68 \mu \mathrm{s} ;$ Figs. 2 and 3 are based on 2 and 3 transmissions, respectively; $v_{\text {alias }}$ $=0.8 \mathrm{~m} / \mathrm{s}$; The sampling frequency is $100 \mathrm{MHz}$, and a parabolic fit is used for interpolation.

From Fig. 2 it is seen that the imprecision (coefficient of variation $)^{[3]}$ is relatively unaffected by integration time, apart from minor effects for $T_{w}=4 / f_{0}$. An incorrect detection (i.e. detection of a sidelobe) is defined as occurring when a detected velocity is outside the range $\left[-v_{\text {alias }}+v_{a} ; v_{\text {alias }}+v_{a}\right]$ where $v_{a}$ is the actual velocity ( $x$-axis). The risk of an incorrect detection is increasing with velocity, as the received signals to be cross-correlated becomes less alike, which will increase the relative value of the sidelobes shown in Fig. 1.

Applying a stationary echo-canceller (SEC) to the received $\mathrm{HF}$ signals has some interesting effects. First of all, at small velocities, consecutive received signals due to the flow are nearly identical. Thus, they cancel out, leaving only noise for the estimation. This results in a very high imprecision and incorrect detections. Second, at higher velocities two different effects are present:

When the time shift is near $(2 n+1) /\left(2 f_{0}\right)$, where $n=0,1$ ... the coherent signals are subtracted out of phase. However, when the time shift is around $n / f_{0}$, the coherent signals are subtracted in phase, giving a degradation of the signal to noise ratio. ${ }^{[2]}$ This effect is only slightly visible in Fig. $3(v=1.6$ $\mathrm{m} / \mathrm{s}$ ) due to the relatively high signal to noise ratio.

The second effect is due to interference in the crosscorrelation function. When the SEC is used, three received signals are needed. If these are considered to be identical, but each time shifted a fixed amount, i.e. $g_{2}(t)=g_{1}\left(t-t_{0}\right)=g_{0}\left(t-2 t_{0}\right)$, then the cross-correlation function

$$
C(\tau)=\int\left[g_{1}(t)-g_{0}(t)\right]\left[g_{2}(t+\tau)-g_{1}(t+\tau)\right] d t,
$$

will consist of three individual functions, where one of these

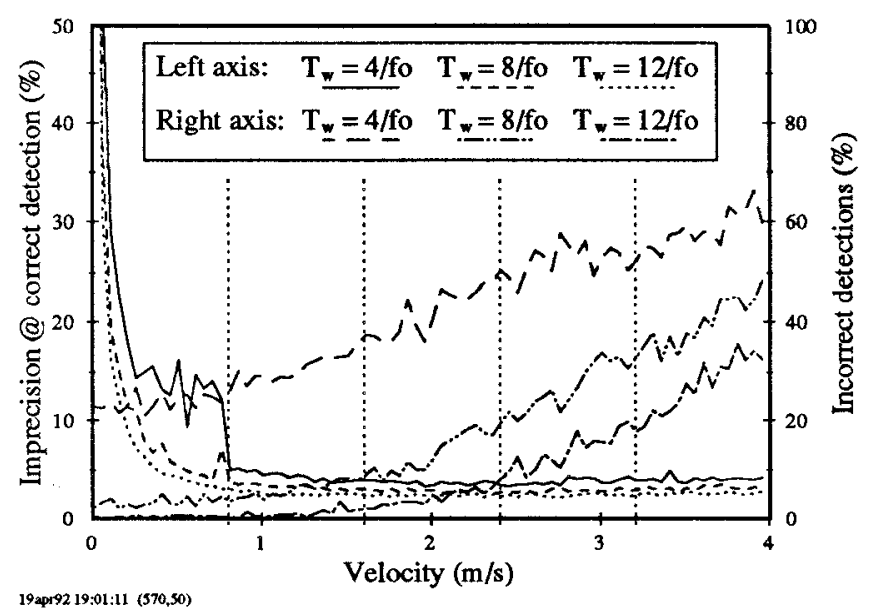

Fig. 2 Imprecision and probability of incorrect detection.

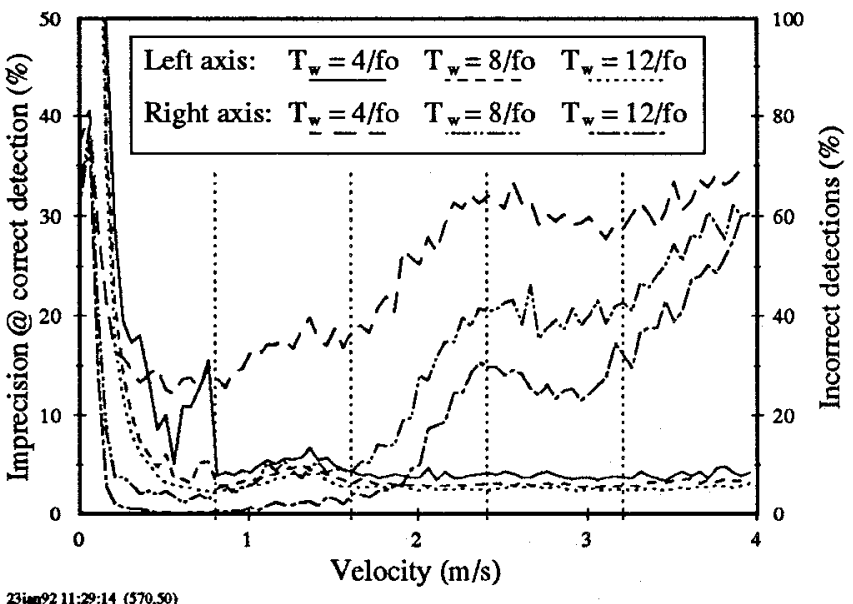

Fig. 3 Imprecision and probability of incorrect detection, when a stationary echo-canceller is used.

is the auto-correlation function of $g_{1}(t)$. For special values of $t_{0}\left(e . g . t_{0}=3 /\left(2 f_{0}\right)\right)$, this function will interfere with the sidelobes of the main cross-correlation function, thereby increasing the risk of detecting a sidelobe. This is clearly seen in Fig. 3, for $v=2.4 \mathrm{~m} / \mathrm{s}$.

\section{CONCLUSIONS}

It has been shown that increasing the segment length $\left(T_{w}\right)$ of the signals to be cross-correlated diminish the risk of detecting an incorrect peak at the expense of degraded depth resolution. The probability has been graphed, and the effect of using a stationary echo-canceller has been demonstrated. Based on these observations, a scheme could be designated, where the approximate location of the peak is found with a large segment length, and then the precise location can be found by recalculating the cross-correlation function with a small segment length.

\section{ACKNOWLEDGMENT}

The author is very thankful for valuable discussions with Associate Prof. Lars-Kai Hansen.

\section{REFERENCES}

[1] Foster, S. G., Embree, P. M, O'Brien, W. D.: Flow velocity profile via time-domain correlation: error analysis and computer simulation. IEEE Trans. on Ultrasonics, ferroel. and freq. contr. Vol 37, no. 2, May 1990.

[2] Jensen, Jørgen Arendt: Detection probabilities for time-domain velocity estimation. IEEE Ultrasonic Symp., Orlando, Florida, Dec. 91.

[3] Wilhjelm, J. E.: Ultrasound FM Doppler system for flow profiling with comparison to PW Doppler systems. PhD thesis, Worcester Polytechnic Institute, MA, USA, 1991. 